\title{
Article \\ Junction Properties Interpretation of Textile Geogrids Using Multi-Junction Clamp
}

\author{
Aram Lee ${ }^{1}$, Yu Yan ${ }^{2} \oplus$, Yuanchun Jin ${ }^{3}$, Jiho Youk ${ }^{4, *}$ and Hanyong Jeon ${ }^{4, *}$ \\ 1 Department of Chemistry and Chemical Engineering, Inha University Graduate School, Incheon 22212, Korea; \\ arlee@koteri.re.kr \\ 2 Industrial Science and Technology Research Institute, Inha University, Incheon 22212, Korea; \\ dusdn@inha.ac.kr \\ 3 China Shanghai Branch, FITI Testing \& Research Institute, Shanghai 201702, China; jinyc@fitiglobal.com \\ 4 Department of Chemical Engineering, Inha University, Incheon 22212, Korea \\ * Correspondence: youk@inha.ac.kr (J.Y.); hyjeon@inha.ac.kr (H.J.); \\ Tel.: +82-32-860-7498 (J.Y.); +82-32-872-1426 (H.J.)
}

check for updates

Citation: Lee, A.; Yan, Y.; Jin, Y.; Youk, J.; Jeon, H. Junction Properties Interpretation of Textile Geogrids Using Multi-Junction Clamp. Appl. Sci. 2021, 11, 6343. https://doi.org/ 10.3390/app11146343

Academic Editors: Patrick A. Fairclough and Han-Yong Jeon

Received: 3 June 2021

Accepted: 5 July 2021

Published: 8 July 2021

Publisher's Note: MDPI stays neutral with regard to jurisdictional claims in published maps and institutional affiliations.

Copyright: (c) 2021 by the authors. Licensee MDPI, Basel, Switzerland. This article is an open access article distributed under the terms and conditions of the Creative Commons Attribution (CC BY) license (https:/ / creativecommons.org/licenses/by/ $4.0 /)$.

\begin{abstract}
In this paper, multi-junction clamp was used for junction strength evaluation under 20 , 50 and $100 \mathrm{~mm} / \mathrm{min}$ of strain rate at ambient condition. One eight rib specimens were gripped in the clamps and each gage length was $50 \mathrm{~mm}, 100 \mathrm{~mm}$ and $150 \mathrm{~mm}$, respectively. Warp knitted and woven type geogrids were used to compare the effects of multi-junction clamping on junction and tensile strength, respectively. The results indicate that junction strength decreased while the number of junctions increased. When the strain rate was increased, junction strength of woven type increased, but there was no effect of strain rate on warp knitted type. The newly designed clamp test for geogrid junction strength in this research is more accurate than the single-junction test, considering the scale effect of specimens.
\end{abstract}

Keywords: multi-junction clamp; junction strength; geogrids; clamp; scale effect

\section{Introduction}

Textile geogrids(referred to as geogrid) are the representative reinforcement materials consisting of connected parallel sets of intersecting ribs with aperture of sufficient size to allow strike-through of surrounding soil, stone, or other geotechnical materials. Thus, geogrids are matrix-like materials with large open spaces called apertures which are typically 10 to $100 \mathrm{~mm}$ between ribs that are called longitudinal and transverse, respectively [1-3]. The network structure of geogrids gives stronger interaction to adjacent soil than other sheet type reinforcement. In general, the interaction between soil and geogrid is divided into three terms; (a) friction of geogrid to adjacent soil, (b) friction soil to soil directly contacted through apertures and (c) passive resistance of cross direction ribs of geogrids. Geogrid imposed loads due to a friction of cross direction rib surface to soil, and passive resistance of cross direction ribs, are transferred through junction to mechanical direction rib. Therefore, sufficient junction strength is needed to carry the induced force [4]. In general, junction efficiency and junction strength per unit width is calculated by a conversion equation that is recommended in GRI GG-2 [5]. The GRI GG-2 test method has an inherent weakness in not being able to take into account the scale effect of geogrid specimens. Most of the geosynthetics being used for civil engineering are used as tensile members, and they are subject to an assessment of their tensile strength by taking a specimen of wide width [6-8]. Therefore, more reliable test methods which include the scale effect are needed. The current trend in the assessment of the tensile strength of geosynthetics is that tensile strength tests on a specimen with a width as wide as possible. This study is a desirable attempt to provide more accurate and reliable test data, considering the scale effect of a specimen. In this study, the multi-junction test method was suggested for the assessment of the geogrids junction strength to consider the aperture size scale effect. 


\section{Experimental}

\subsection{Preparation of Geogrids}

PET filament woven and warp knitted geogrids with PVC coating were used. Figure 1 shows a picture of the geogrid used in this study. The specification and physical properties of geogrids were confirmed and are represented in Table 1.

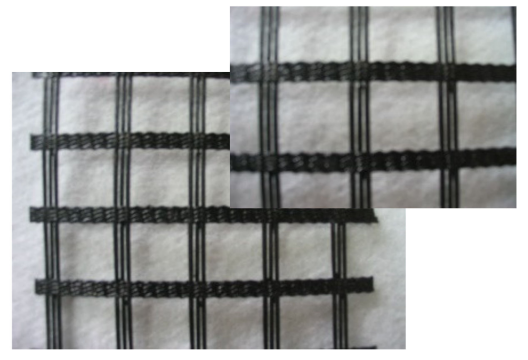

(a) Woven type

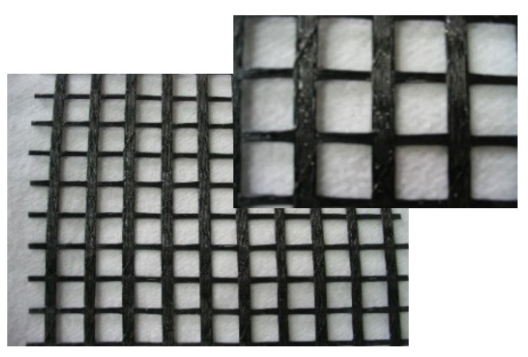

(b) Warp knitted type

Figure 1. Photographs of geogrid specimens.

Table 1. Specifications of geogrids.

\begin{tabular}{|c|c|c|c|c|c|c|}
\hline \multirow{3}{*}{ Geogrid } & \multirow{3}{*}{$\begin{array}{l}\text { Raw Material } \\
\text { /Coating Agent }\end{array}$} & \multirow{3}{*}{$\begin{array}{c}\text { Number } \\
\text { of Ribs (/m) }\end{array}$} & \multicolumn{4}{|c|}{ Mechanical Properties } \\
\hline & & & \multicolumn{2}{|c|}{$\begin{array}{l}\text { Ultimate Strength } \\
\text { (ton } / \mathrm{m})\end{array}$} & \multicolumn{2}{|c|}{$\begin{array}{l}\text { Elongationat } \\
\text { at Break (\%) }\end{array}$} \\
\hline & & & MD & CMD & MD & CMD \\
\hline W-GG-1 & $\mathrm{PET} / \mathrm{PVC}$ & 47 & 6 & 3 & 12 & NA \\
\hline W-GG-2 & $\mathrm{PET} / \mathrm{PVC}$ & 38 & 10 & 3 & 12 & NA \\
\hline WK-GG-1 & $\mathrm{PET} / \mathrm{PVC}$ & 42 & 6 & 3 & 12 & NA \\
\hline WK-GG-2 & $\mathrm{PET} / \mathrm{PVC}$ & 38 & 10 & 3 & 12 & NA \\
\hline
\end{tabular}

$\mathrm{MD}$ is machine direction and CMD is cross machine direction, respectively.

\subsection{Single and Multi-Junction Tests}

A testing apparatus as described in Figure 2a is used mainly for the assessment of only one junction strength of a geogrid, according to GRI GG-2. The test method uses a clamping fixture that grips the transverse ribs of the geogrid immediately adjacent to and on each side of the longitudinal rib. The lower portion of the longitudinal rib is gripped in a standard clamp, and each clamp is mounted in a tensile testing machine, where the test specimen is pulled apart. This method gives single-junction strength, junction efficiency and geogrids junction strength per unit width. The first values of single-junction strength are obtained directly from the test results. In previous research old designed multi-junction clamp was used to test geogrids junction strength (Figure $2 b$ ). 


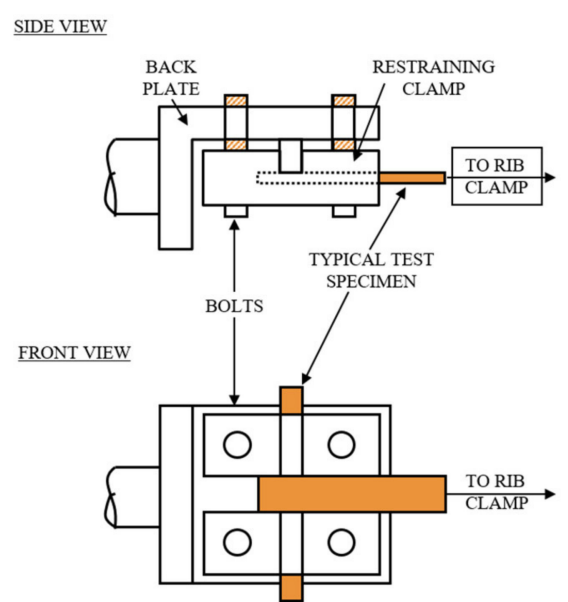

(a)

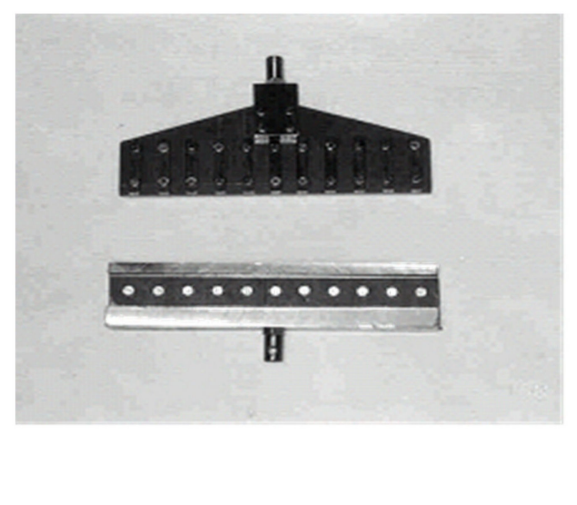

(b)

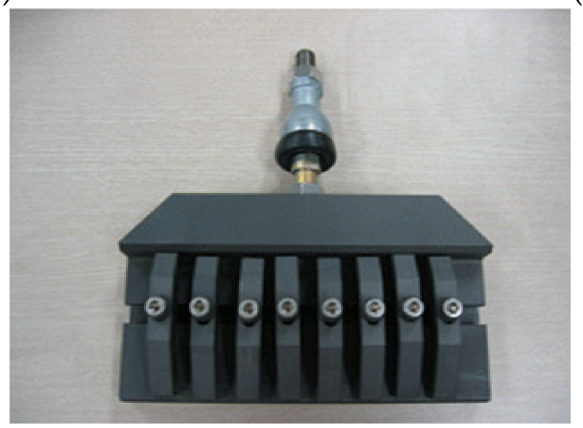

(c)

Figure 2. Overview of junction test clamp: (a) single-junction test clamps; (b) old designed multijunction clamp; (c) newly designed multi-junction clamp.

The basic concept for this equipment was to widen the single-junction test clamp and the point-to-point length was determined by the aperture size of test conditions. For the old designed multi-junction test, a point-to-point length was $25 \mathrm{~mm}$ and the width of the clamp was $280 \mathrm{~mm}$. The upper clamp has 11 gripping points for junctions and the lower clamp is a kind of flat type which also has 11 gripping points $[9,10]$. Using this modified method of determination, the geogrid junction strength should be more reasonable than the singlejunction test. However, this kind of clamp is only suitable in testing the geogrids which aperture size was $25 \mathrm{~mm}$. A newly developed multi-clamp was used to test junction strength. Figure 2 shows a composed drawing of multi-junction grip for junction strength testing of geogrid. The clamp is composed of a set of single grips in parallel. The pitch of the clamp grip can be freely adjusted. The total number of the restraining grip is 11 . In the lower part, a normal type rib clamp was used. Figure 2c shows the newly designed multi-junction clamps. In order to evaluate the effectiveness of the newly developed multi-junction testing apparatus and test condition (strain rate, specimen length and junction numbers), multi-junction clamp was used for junction strength with 20,50 and $100 \mathrm{~mm} / \mathrm{min}$ test speed at ambient condition. One eight rib specimens were gripped in the clamps and the gage length was $50 \mathrm{~mm}, 100 \mathrm{~mm}$ and $150 \mathrm{~mm}$. Furthermore, singlejunction test samples were prepared according to the GRI-GG 2 test method while the test process was according to ASTM D4595 [11] for united test condition. The multi-junction test has been used under the same testing conditions and procedure as ASTM D 4595 except for the clamp devices. The multi-junction clamp proposed in this paper is a clamp that minimizes the error of the test result due to slipping by improving the slippage of the specimen held by the clamp compared to the conventional clamp. 


\subsection{Single and Wide-Width Tensile Tests}

Single and wide-width tensile strength test conditions were utilized according to the ASTM D4595 test method. Roll grip clamp was used in this test and total test conditions for junction strength are representedin Table 2.

Table 2. Specifications of test conditions.

\begin{tabular}{ccccc}
\hline Properties & $\begin{array}{c}\text { Single-Junction } \\
\text { Test }\end{array}$ & $\begin{array}{c}\text { Multi-Junction } \\
\text { Test }\end{array}$ & $\begin{array}{c}\text { Single Tensile } \\
\text { Test }\end{array}$ & $\begin{array}{c}\text { Wide-Width } \\
\text { Tensile Test }\end{array}$ \\
\hline $\begin{array}{c}\text { Scale effect } \\
\text { Slip }\end{array}$ & $\begin{array}{c}\text { Unconsidered } \\
\text { Unconsidered } \\
\text { Strain rate }\end{array}$ & $\begin{array}{c}\text { Considered } \\
\text { Unconsidered } \\
(\mathrm{mm} / \mathrm{min})\end{array}$ & $\begin{array}{c}\text { Unconsidered } \\
\text { Considered }\end{array}$ & $\begin{array}{c}\text { Considered } \\
\text { Considered }\end{array}$ \\
$\begin{array}{c}70 \\
\text { Specimen width }\end{array}$ & $1 \mathrm{rib}$ & $\begin{array}{c}(20,50,100) \\
1 \sim 8 \mathrm{rib}\end{array}$ & 70 & 70 \\
$\begin{array}{c}\text { Specimen length } \\
(\mathrm{mm})\end{array}$ & $300 \mathrm{~mm})$ & $1 \mathrm{rib}$ & $200 \mathrm{~mm}$ \\
\hline
\end{tabular}

\section{Theoretical Background}

In this study a single-junction test was carried out using the multi-junction clamp device. From the test results, geogrid junction strength per unit width and junction efficiency (standard) is calculated:

$$
\begin{gathered}
\mathrm{J}_{\text {rib }}=\mathrm{I} / \mathrm{n} \\
\mathrm{J}_{\text {grid }}=\left(\mathrm{J}_{\text {rib }}\right)\left(\mathrm{n}_{\text {junction }}\right) / \mathrm{w} \\
\mathrm{E}_{\text {junction }}=\left(\mathrm{J}_{\mathrm{rib}} / \mathrm{T}_{\text {rib }}\right) \times 100
\end{gathered}
$$

where, $\mathrm{J}_{\text {rib }}=$ single-junction strength (average); $\mathrm{J}_{\mathrm{i}}=$ single-junction strength of each junction (experimental value); $\mathrm{n}=$ total number of test specimens; $\mathrm{I}_{\text {grid }}=$ geogird junction strength per unit width; $\mathrm{n}_{\text {junction }}=$ number of junctions in a unit width; $\mathrm{w}=$ unit width (typically $1 \mathrm{~m}$ or $1 \mathrm{ft}$ ); $\mathrm{E}_{\text {junction }}=$ junction efficiency; $\mathrm{T}_{\text {rib }}=$ tensile strength of single rib (by ASTM D6637 [12]).

The experimental results were reported in terms of the multi-junction strength per specific number of ribs and the geogirds junction strength per unit width computed by the following equation:

$$
\begin{gathered}
\mathrm{J}_{\text {multi-rib }}=\sum_{\mathrm{i}=1}^{\mathrm{n}} \mathrm{J}_{\mathrm{i}-\text { multi }} / \mathrm{n} \\
\mathrm{J}_{\text {grid }}=\frac{\left(\mathrm{J}_{\text {multi-rib }}\right)\left(\mathrm{n}_{\text {junction }}\right)}{(\mathrm{W})\left(\mathrm{n}_{\text {test }}\right)} \\
\mathrm{E}_{\text {junction }}=\frac{\mathrm{J}_{\text {multi-rib }}}{\mathrm{T}_{\text {wide-width }}} \times 100
\end{gathered}
$$

where $J_{\text {multi-rib }}=$ junction strength of a specimen width i number of junctions (average); $\mathrm{J}_{\mathrm{i}-\mathrm{multi}}=$ each junction's junction strength width i number of junctions (experimental value); $\mathrm{n}=$ total number of test specimens; $\mathrm{J}_{\text {grid }}=$ geogird junction strength per unit width; $\mathrm{n}_{\text {junction }}$ = number of geogird junction per unit width; $\mathrm{W}=$ unit width (typically $1 \mathrm{~m}$ or $1 \mathrm{ft}$ ); $\mathrm{n}_{\text {test }}=$ number of junction in the tested specimen; $\mathrm{T}_{\text {grid }}=$ geogrid tensile strength per unit width .

\section{Results and Discussion}

\subsection{Optimization of Geogrid Multi-Junction Strength Evaluation}

Table 3 shows the test results of single-junction strength classified by grip position. In the GRI test method, the upper grip position is as close as possible to the vertical center rib. However, this newly developed test method recommends the upper grip position in the middle of the vertical center rib. The values of single-junction strength tested by the newly developed method are less than those tested according to GRI GG-2 for woven and warp knitted types. The values of elongation displayed in an opposite trend. GRI 
GG-2 determines the specimen in an ideal condition in order to investigate the maximum junction strength. However, in soil geogrid cross rib suffers variable curvature ribbing, and the peak of the curvature is the center bearing rib. Therefore, gripping the center of the cross rib is more appropriate to represent actual utilizing condition.

Table 3. Single-junction test results by grip position.

\begin{tabular}{|c|c|c|c|c|c|c|c|}
\hline \multirow{2}{*}{ Geogrid } & \multirow{2}{*}{ Value } & \multicolumn{2}{|c|}{$20 \mathrm{~mm} / \mathrm{min}$} & \multicolumn{2}{|c|}{$50 \mathrm{~mm} / \mathrm{min}$} & \multicolumn{2}{|c|}{$100 \mathrm{~mm} / \mathrm{min}$} \\
\hline & & GRI & New & GRI & New & GRI & New \\
\hline \multirow{2}{*}{ W-GG-2 } & $\mathrm{J}_{\text {single }}(\mathrm{kgf})$ & 19.2 & 18.5 & 19.8 & 18.8 & 20.4 & 19.7 \\
\hline & Elongation (mm) & 3.9 & 4.1 & 4.2 & 4.3 & 4.2 & 4.2 \\
\hline \multirow{2}{*}{ WK-GG-2 } & $\mathrm{J}_{\text {single }}(\mathrm{kgf})$ & 39.1 & 37.7 & 39 & 38 & 39.6 & 38 \\
\hline & Elongation (mm) & 7.0 & 7.4 & 6.4 & 7.4 & 6.6 & 7.0 \\
\hline
\end{tabular}

As with the single-junction test, the average junction strength per one rib and the geogrids junction strength per unit width are also calculated by using multi-junction test results. Firstly, geogrids which have 1-8 junctions were tested and curves of junction strength to number of junction were plotted. Secondly, normalized values of junction strength were calculated for each sample. Figure 3 shows the junction strength plotted against the number of junctions in different specimen length. Results of junction strength were carried out with different lengths showing that there was no change in junction strength at rupture point because woven and warp knitted materials contained PET filament. Therefore, in order to derive precise data, the same conditions except for specimen length were summarized and analyzed.

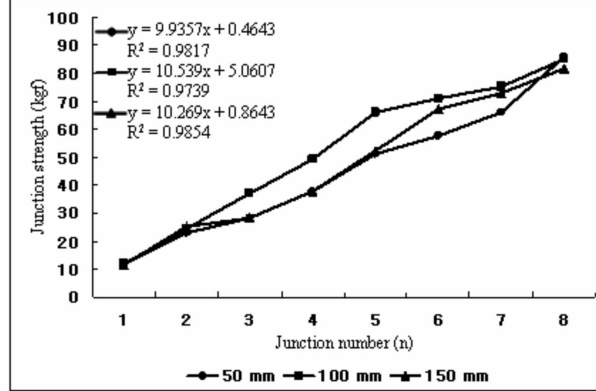

(a) W-GG-1

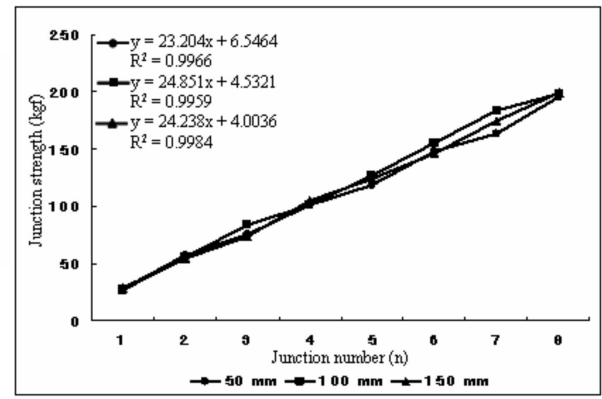

(c) WK-GG-1

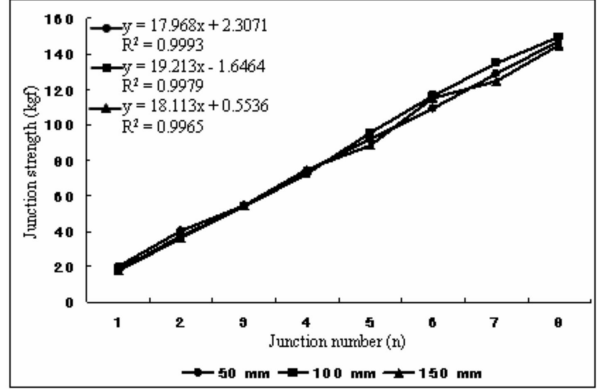

(b) W-GG-2

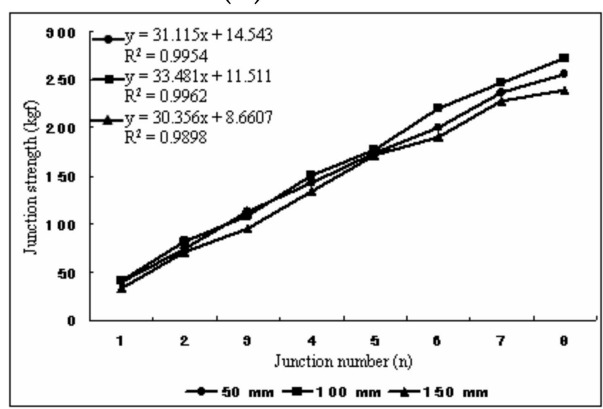

(d) WK-GG-2

Figure 3. Regression analysis for the number of junctions versus junction strength with specimen length for geogrids.

Figure 4 shows the results of regression analysis on the number of junctions versus junction strength with strain rate of geogrids. For woven type geogrids, all the plots were divided uniformly and the curves showed the same trend. Hence, the data have good reliability. Junction strength for geogrids were linearly increased with the numbers of junction and fitting was excellent with an R-squared value greater than 0.99 . The difference 
is considered to be caused by scale effect and variation in the difference of manufactured product. For warp knitted geogrids, each normalized value is less than the value tested by single-junction test because of scale effect. The figure illustrates that junction strength strongly depends on junction number. When the numbers of junction point are less than three (including three), the normalized junction strength of woven type decreases markedly. When the numbers of junction point ranged from four to eight (including eight), the normalized junction strength of woven type changed slightly.

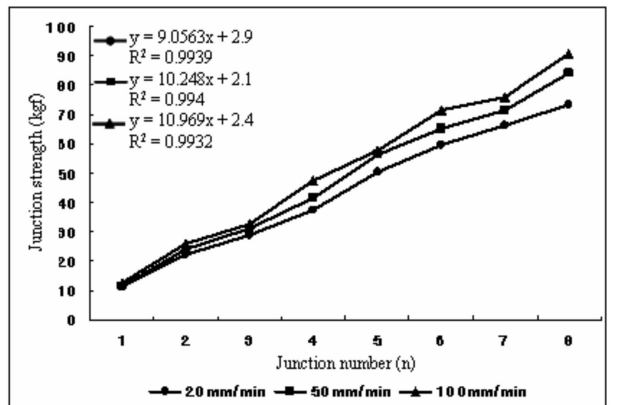

(a) W-GG-1

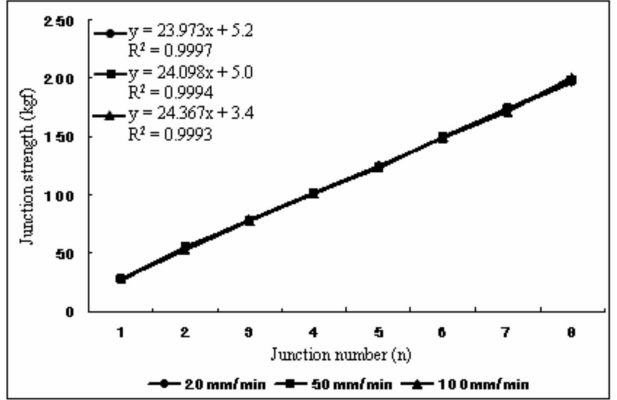

(c) WK-GG-1

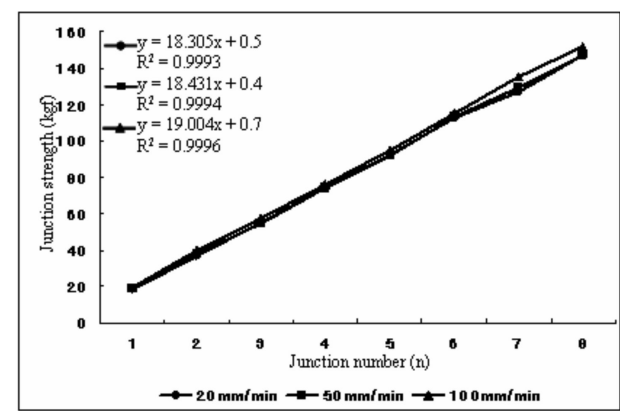

(b) W-GG-2

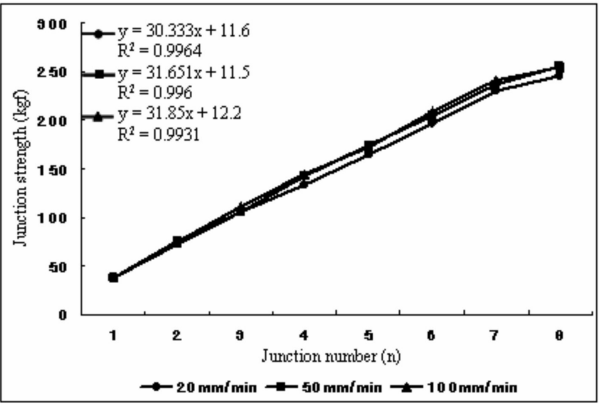

(d) WK-GG-2

Figure 4. Regression analysis for the number of junctions versus junction strength with strain rate for geogrids.

Figure 5 shows that woven and warp knitted type geogrids showed residual strength increase over the peak strength. When junction part of woven type geogrid junctions were pulled out, load-strain curve was drawn by by considering effect of each junction part mathematically and peak point appearance was not affected by any member over the peak strength. Once the junction number was more than four, their mutual-effect nearly reached equilibrium and the data were stabilized. Woven type geogrid junction strength increased with strain rate because of pulling-out mechanism. When strain rate increased, abrasion force also increased. Junction strength of warp knitted type lineally decreased while junction number increased. Therefore, when multi-junction strength was tested, peak point appeared as long as any of the junctions were broken up. There is no effect of strain rate on warp knitted type. The result indicated that the variable of a specimen with less than three junctions was caused by unstable balance and without considering scale effect sufficiently. From the results of the multi-junction test, it is indicated that a specimen with more than four junctions can provide reliable data of junction strength with scale effect taken into consideration. 


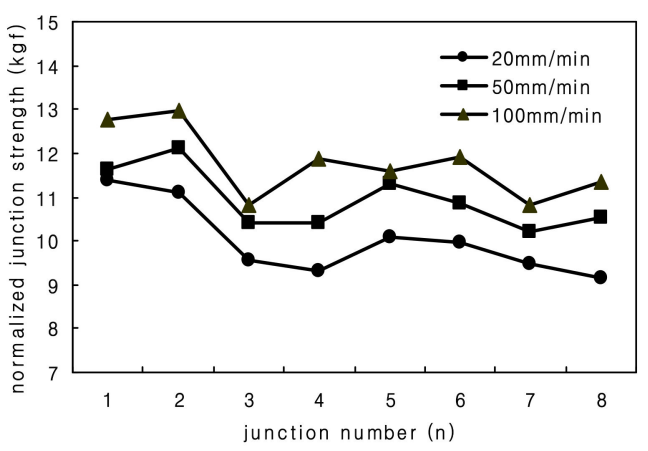

(a) W-GG-1

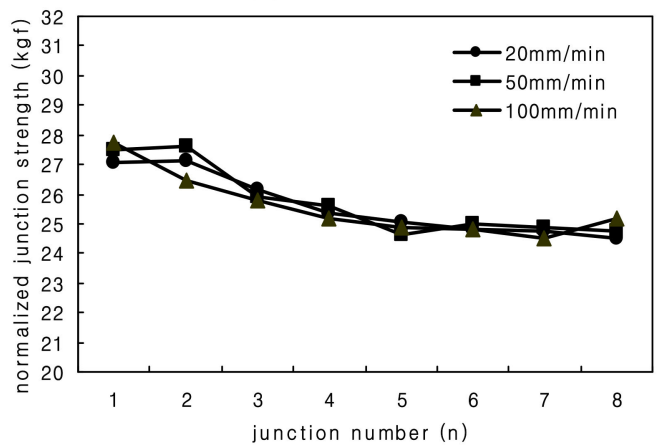

(c) WK-GG-1

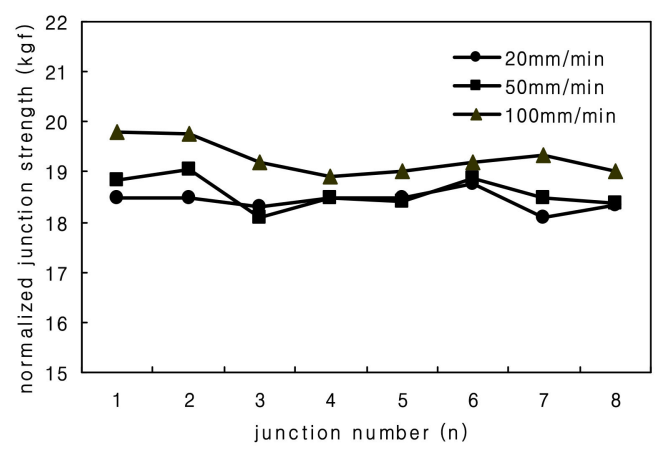

(b) W-GG-2

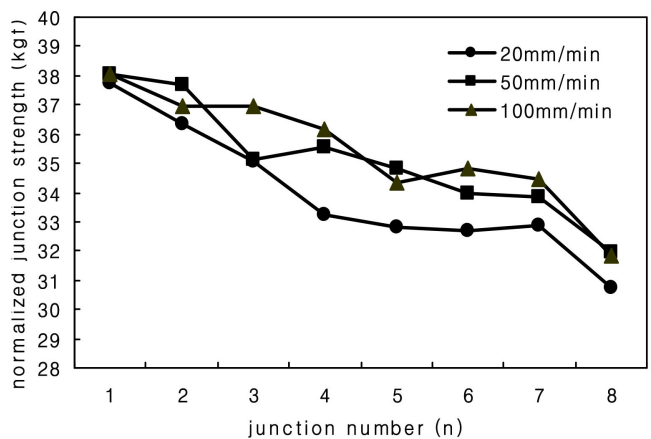

(d) WK-GG-2

Figure 5. Relationship between the numbers of junctions versus normalized junction strength with strain rate.

Figure 6 shows the standard deviation data of normalized value plotted against junction number. As a result, the variables for specimens with fewer than three joints were irregularly affected by the mutual influence of the junction parts, and the scale effect of the junction parts did not have a significant effect. When the junction number was more than four (including four), the value of standard deviation decreased slightly. From this review, it is seen that the normalization of junction strength is more reasonable with increasing of junctions. Therefore, in order to consider the sufficient scale effect, the junction width should be as wide as possible. Considering various factors effecting the results of junction strength, and according to the GRI-GG2 test method, In the multi-junction stregnth test, the distance between grips was maintained at a minimum of $100 \mathrm{~mm}$, and the clamp width was set to $200 \mathrm{~mm}$, and the strain rate was $10 \pm 3 \% / \mathrm{min}$.

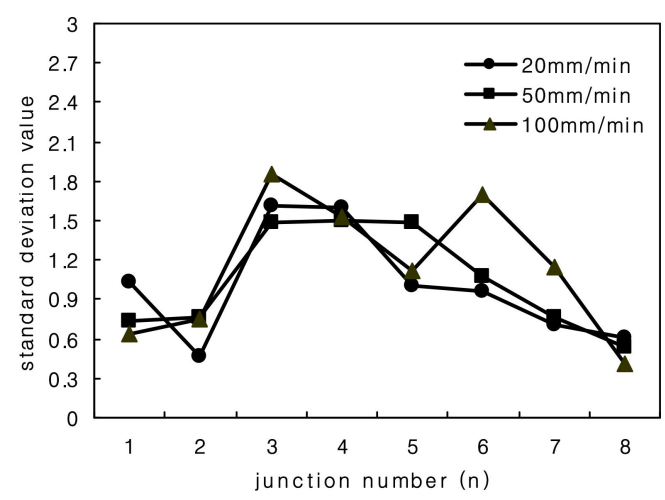

(a) W-GG-1

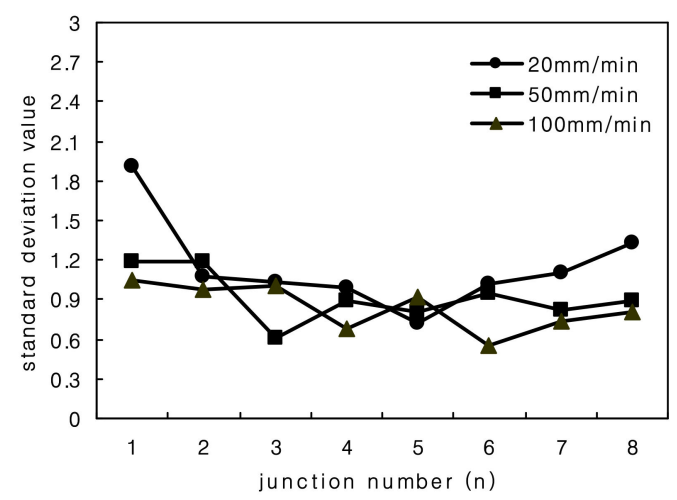

(b) W-GG-2

Figure 6. Cont. 


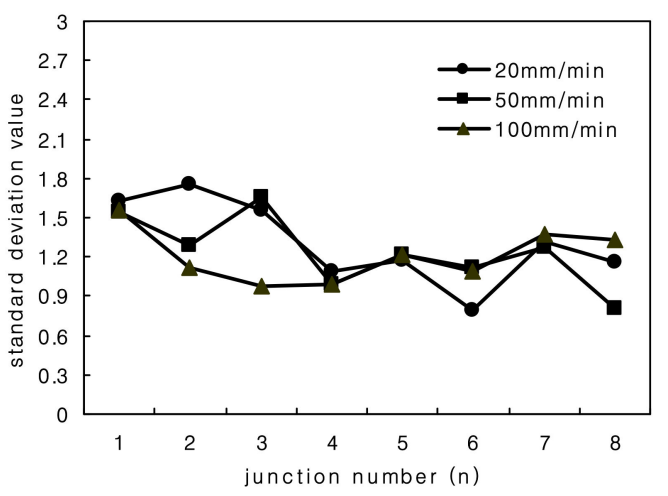

(c) WK-GG-1

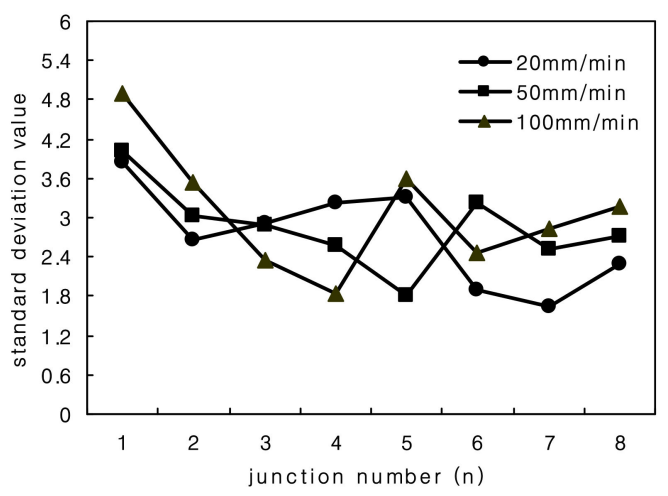

(d) WK-GG-2

Figure 6. Standard deviation data of normalized value plotted against junction number.

\subsection{Analysis of Tensile Property and Junction Property for Geogrids}

The results of the multi-junction test proposed in this study are summarized in Table 4.

Table 4. Results of multi-junction strength test.

\begin{tabular}{cccccccc}
\hline \multicolumn{2}{c}{ W-GG-1 } & \multicolumn{2}{c}{ W-GG-2 } & \multicolumn{2}{c}{ WK-GG-1 } & \multicolumn{2}{c}{ WK-GG-2 } \\
\hline $\begin{array}{c}\text { Strength } \\
\mathbf{( k g f )}\end{array}$ & $\begin{array}{c}\text { Strain } \\
\mathbf{( \% )}\end{array}$ & $\begin{array}{c}\text { Strength } \\
\mathbf{( k g f )}\end{array}$ & $\begin{array}{c}\text { Strain } \\
\mathbf{( \% )}\end{array}$ & $\begin{array}{c}\text { Strength } \\
\mathbf{( k g f )}\end{array}$ & $\begin{array}{c}\text { Strain } \\
\mathbf{( \% )}\end{array}$ & $\begin{array}{c}\text { Strength } \\
\mathbf{( k g f )}\end{array}$ & $\begin{array}{c}\text { Strain } \\
\mathbf{( \% )}\end{array}$ \\
\hline 115.74 & 3.5 & 166.3 & 4.0 & 273.6 & 8.86 & 253.3 & 7.3 \\
\hline
\end{tabular}

The results of the single and multi-junction tests were compared and analyzed, along with the single and wide-width tensile tests. Equations (1)-(3) were applied in order to calculate the geogrid junction strength per unit width and junction efficiency (standard). These calculated values were then compared with the values in the multi-junction strength test calculated from Equations (4)-(6) (proposed). Similar to the tensile test, comparing the junction strength from the single-junction test with the multi-junction test, multijunction test values are smaller than single-junction test values. This difference is due to the scale effect, and the multi-junction test is more accurate than the single-junction test. The scale effect of tensile and junction tests is shown in Table 5. Scale effect exists in both the tensile and junction tests. However, comparing the value of the single tensile test and wide-width tensile tests, there is a slight change because of good stability in the property of tensile strength and handling process. The value of scale effect in junction test is much lower than that of tensile test, especially of woven type. This is due to single-junction strength data of the product distributing more disordered than the single tensile test, and that multi-junction clamp has a higher tendency to error during handling. Therefore, the multi-junction test results in large strength reduction.

Table 5. Results of tensile and junction test.

\begin{tabular}{ccccccc}
\hline Geogrid & $\begin{array}{c}\mathbf{T}_{\text {single-rib }} \\
\mathbf{( T / m )}\end{array}$ & $\begin{array}{c}\mathbf{T}_{\text {wide-width }} \\
\mathbf{( T / m )}\end{array}$ & $\mathbf{T}_{\text {scale effect }}$ & $\begin{array}{c}\mathbf{J}_{\text {single-rib }} \\
\mathbf{( T / m )}\end{array}$ & $\begin{array}{c}\mathbf{J}_{\text {wide-width }} \\
\mathbf{( T / m )}\end{array}$ & $\mathbf{J}_{\text {scale effect }}$ \\
\hline W-GG-1 & 8 & 7.8 & 0.97 & 1.43 & 1.29 & 0.90 \\
W-GG-2 & 12.8 & 13.1 & 1.02 & 1.52 & 1.2 & 0.79 \\
WK-GG-1 & 7.6 & 7.0 & 0.92 & 0.56 & 0.54 & 0.97 \\
WK-GG-2 & 13 & 12.8 & 0.98 & 0.86 & 0.79 & 0.92 \\
\hline
\end{tabular}

Table 6 presents junction efficiency derived from Equations (3) and (6). Compared to the junction efficiency of the single-junction test with the multi-junction test, multi-junction test values are slightly lower than single test values except for the six ton woven type. 
This difference is due to the scale effect of the multi-junction test which is bigger than the wide-width tensile test. Using the multi-junction test method can be more accurate in representing junction efficiency than the single-junction test, considering scale effect.

Table 6. Junction efficiency of geogrids.

\begin{tabular}{ccccc}
\hline \multirow{2}{*}{ Value } & \multicolumn{4}{c}{ Geogrid } \\
\cline { 2 - 5 } & W-GG-1 & W-GG-2 & WK-GG-1 & WK-GG-2 \\
\hline E $_{\text {single }}$ & 7.38 & 6.64 & 18 & 11.9 \\
E $_{\text {wide-width }}$ & 7.77 & 5.76 & 16.5 & 9.15 \\
\hline
\end{tabular}

Figure 7 shows the difference between wide-width and junction-width tensile tests. The value of tensile strength, which uses the multi-junction clamp, is markedly less than using the roll clamp. The significant distance due to slippage occurs during the multijunction test.
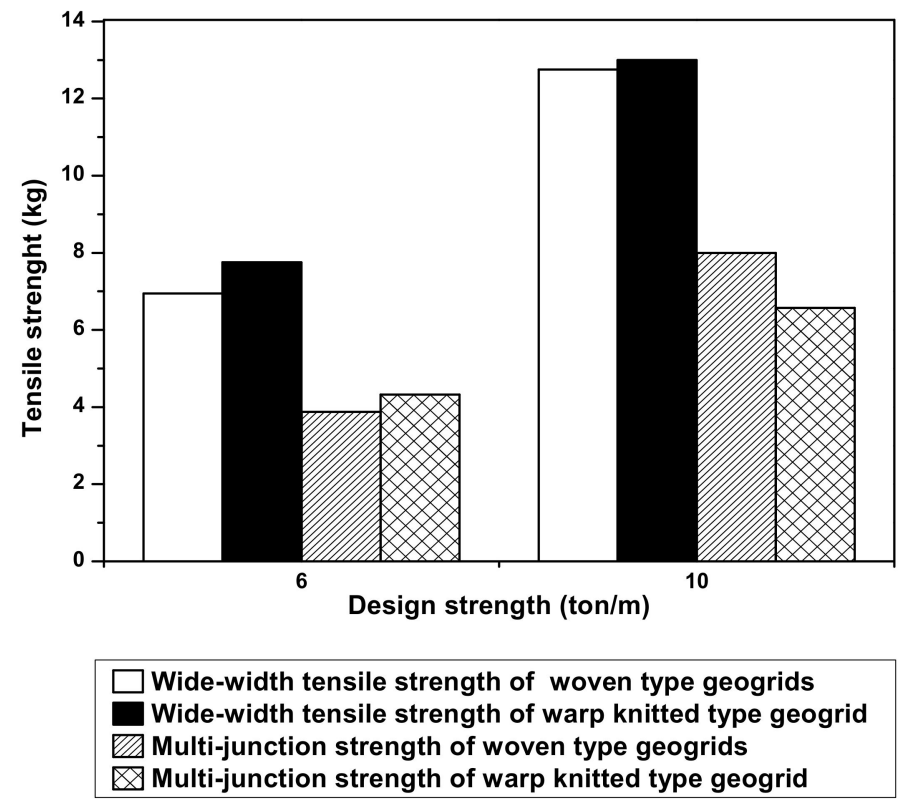

Figure 7. Tensile strength measured by wide-width and junction-width tensile test method.

\section{Conclusions}

The total trend of junction strength of geogrid decreased with the number of junctions. When strain rate increased, geogrids of woven type junction strength increased, while there is no effect by strain rate on warp knitted type. The junction strength with junction numbers under different strain rate showed the same trend in both woven and warp knitted types. Specimen length does not affect junction strength. Similar to the tensile test, geogrid junction strength values from the multi-junction test are lower than those from the single-junction test due to the scale effect of the specimen. The junction strength correction coefficient value is lower than tensile strength, especially with warp knitted type, which shows a marked decrease in junction strength. It is appropriate to evaluate the geogrid junction strength and junction efficiency by using the geogrid multi-junction test method considering scale effect. In order to minimize the multi-junction strength measurement error of geogrid, the mutual influence of factors such as cyclic load time, polymer raw material, maximum grain size, and the gradation and the shape of the soil particles (rounded/angular) was quantitatively evaluated. It is thought that further research to interpret this should be carried out. 
Author Contributions: Conceptualization, J.Y. and H.J.; methodology, H.J.; validation, A.L., Y.Y. and Y.J.; formal analysis, A.L.; investigation, Y.Y.; data curation, Y.J.; writing—original draft preparation, A.L.; writing—review and editing, J.Y. and H.J.; supervision, J.Y. and H.J.; project administration, H.J.; funding acquisition, H.J. All authors have read and agreed to the published version of the manuscript.

Funding: This research was supported by a grant (10083576) from the Industrial Material Core Technology Research Program funded by the Ministry of Trade, Industry and Energy of the Korean government.

Conflicts of Interest: The authors declare no conflict of interest.

\section{References}

1. Koerner, R.M. Designing with Geosynthetics, 5th ed.; Person Education Inc.: New Jersey, NJ, USA, 2005.

2. Wilson-Fahmy, R.; Koerner, R.M.; Fleck, J.A. Unconfined and Confined Wide Width Testing of Geosynthetics. In Geosynthetic Soil Reinforcement Testing Procedures; ASTM STP, 1190, Cheng, S.J., Eds.; ASTM: West Conshohocken, PA, USA, $1993 ;$ pp. $49-63$.

3. Kinney, T.C. Determining the Secant Aperture Stability Modulus of a Geogrid; Shannon and Wilson Inc.: Seattle, WA, USA, 2000 ; p. 6.

4. Hufenus, R. Strength reduction factors due to installation damage of reinforcing geosynthetics. Geotext. Geomembr. 2005, 23, 401-424. [CrossRef]

5. GRI. GRI Test Method GG-2, Geogrid Junction Strength; Geosynthetics Research Institute Drexel University: Philadelphia, PA, USA, 2002.

6. Fonyo, B.; Sacchetti, A. Design Software Comparison of Reinforced Steep Slopes. In Proceedings of the 9th ICG Conference, Guarujá, Brazil, 23-27 May 2010; pp. 1819-1822.

7. Han, J.; Akins, K. Use of Geogrid Reinforced and Pile Supported Earth Structures. In Proceedings of the International Deep Foundations Congress, Orlando, FL, USA, 14-16 February 2002; pp. 668-679.

8. Sheridan, T.G. Geosynthetic Materials Play a Role in New Underground Stormwater Detention System. Geosynth. Mag. 2010, 28 , 35-41.

9. Jeon, H.Y.; Yuu, J.J. Assessment of junction strength of geogirds by a multi-junction test method. Polym. Test. 2003, 2003. 22, 267-274. [CrossRef]

10. Jeon, H.Y.; Yuu, J.J. Test method of wide-width geogrid junction strength. In Proceedings of the 1st China International Geo-synthetics Conference, Shanghai, China, 8-10 June 2000; pp. 188-197.

11. ASTM International. ASTM D4595, Standard Test Method for Tensile Properties of Geotextiles by the Wide-Width Strip Method; ASTM International: West Conshohocken, PA, USA, 2017.

12. ASTM International. ASTM D6637, Standard Test Method for Determining Tensile Properties of Geogrids by the Single or Multi-Rib Tensile Method; ASTM International: West Conshohocken, PA, USA, 2011. 